\title{
Development of a method for melamine determination in beer and beer-type beverages by GC-MS/MS
}

\author{
Michaela Malečkovái,2,, Tomáš Vrzal ${ }^{1}$, Jana Olšovská ${ }^{1}$ \\ Research Institute of Brewing and Malting, Plc., Lípová 511/15, \\ Prague, Czech Republic \\ 2 Charles University, Faculty of Science, Department of Analytical \\ Chemistry, Albertov 6, Prague, Czech Republic
}

*corresponding author: maleckova@beerresearch.cz

\begin{abstract}
Based on the European regulation, the Czech Association of Breweries and Malthouses recommends $2.5 \mathrm{mg} / \mathrm{kg}$ as maximum permitted concentration of melamine for beer, barley, malt, hop, and their products. For this reason, the first analytical method for melamine determination in beer and beer-type beverages was developed. The sample preparation included ion-exchange solid-phase extraction and subsequent derivatization with BSTFA. Qualitative and quantitative analysis was performed by gas chromatography with tandem mass spectrometry. Validation parameters of the method, such as limits of detection and quantification were $0.1 \mathrm{mg} / \mathrm{L}$ and $0.4 \mathrm{mg} / \mathrm{L}$, respectively. Extended uncertainty of the final method was evaluated to $0.1 \mathrm{mg} / \mathrm{L}$. The method was applied on twenty samples of beer lagers, or other beer styles; all had the level of melamine under the limit of quantification $(<0.4 \mathrm{mg} / \mathrm{L})$.
\end{abstract}

Key words: beer, gas chromatography, melamine, tandem mass spectrometry

\section{Introduction}

Melamine (1,3,5-triazine-2,4,6-triamine) is generally used as an additive for plastics, glues or paint colors. In the past years, it was abused by the Asian food industry as a supplement apparently increasing nutritious quality of a product (WHO, 2008). Since one molecule of melamine contains six nitrogen atoms (Figure 1), it falsely rises the total nitrogen determination, which is used for the evaluation of a protein content. Even though the toxicity of isolated melamine has not been proved, its presence in food deceives consumers and could be harmful (WHO, 2008). For instance, it could form insoluble crystals with other triazine derivatives (e.g. by-products of melamine synthesis) that may cause kidney stones or even renal failure (Dobson, 2008; Skinner, 2010).

In connection with suspicious increase in health problems of targeted customers, melamine was detected primarily in pet food (Dobson, 2008) or infant nutrition food (Skinner, 2010). Therefore, several analytical methods for melamine determination in various matrices has<smiles>Nc1nc(N)nc(N)n1</smiles>

Figure 1 Chemical structure of melamine

been developed. For instance, for dried or fresh dairy products (Cai, 2008; Zhao, 2013; Faraji, 2017), drinking water and wastewater (Beltrán-Martinnavaro, 2013), fish and pork kidney (Nochetto, 2013; Beltrán-Martinavarro, 2014), or body fluids (Marco-Peiró, 2012). Various sample preparation techniques were used for extraction of melamine from sample matrices, e.g., ion-exchange 
solid-phase extraction (SPE) (Cai, 2008; Zhao, 2013), cloud-point extraction (Nascimento, 2015), or dispersive liquid-liquid microextraction (Mirzajani, 2016; Faraji, 2017). Qualitative and quantitative analyses were usually based on separation techniques, such as liquid chromatography with the fluorescence or spectrophotometric detection (de Lourdes Mendes Finete, 2014; Faraji, 2017), micellar liquid chromatography (Peris-Vicente, 2016), capillary zone electrophoresis (Demirhan, 2015), and gas or liquid chromatography with tandem mass spectrometry (Cai, 2008; Nochetto, 2013; Zhao, 2013). For gas chromatographic analysis, derivatization by $\mathrm{N}, \mathrm{O}$-bis(trimethylsilyl)trifluoroacetamide (BSTFA) was used to increase volatility of melamine (Cai, 2008; Zhao, 2013). Another derivatization by dapsyl chloride was used to increase detection sensitivity of liquid chromatography with spectrophotometric detection (Faraji, 2017). Besides separation techniques, melamine was further determined by molecularly imprinted impedimetric sensors (Wu, 2012), electrochemical sensors (Zhao, 2019), electron fluorescence (Nascimento, 2015), and by ion-mobility spectrometry (Mirzajani, 2016). Although many analytical techniques were developed, only a limited number of them was applied on various food and beverages (except milk products), even though the European regulation (EU No. 594/2012/ES) from 2012 stated maximum permitted concentration to $2.5 \mathrm{mg} / \mathrm{kg}$ for food and beverages in general.

This paper presents the first method for melamine determination in beer. It reacts to the recommendation of the Czech Association of Breweries and Malthouses (CABM), from 2018, which according to European regulation (EU No. 594/2012/ES) lists the same maximum permitted level of melamine in beer, ciders, barley, malt, hop, and their products. Based on these criteria, the authors of this paper developed an analytical method for the determination of melamine, consisting from the SPE preparation and subsequent analysis by gas chromatography with tandem mass spectrometry (GC-MS/MS). Finally, the developed method was applied on twenty beer samples.

\section{Material and Methods}

\subsection{Chemicals and Materials}

Ammonium hydroxide solution (25\%), pyridine ( $\geq$ 99.8\%), melamine (99.95\%), N,O-bis(trimethylsilyl) trifluoroacetamide with trimethylchlorosilane (BSTFA + TMCS, 99:1), and SPE columns Discovery DSC-SCX (500 $\mathrm{mg}, 3 \mathrm{~mL}$ ) were obtained by Sigma-Aldrich. Formic acid (98-100\%) and methanol ( $\geq 99.9 \%$ ) were produced by Riedel-de Haën and Honeywell, respectively.

\subsection{Sample preparation}

Given beers were produced and sampled by Czech, Polish, Hungarian and Romanian breweries, and consisted of beer lagers (11 samples) and other beer styles ( 9 samples). The samples were prepared according to the method described above (Cai, 2008). A beer sample was degassed by ultrasonication for 5-10 min, and subsequently acidified by formic acid to concentration $1 \mathrm{~mL} / \mathrm{L}$. The SPE sorbent was conditioned by $3 \mathrm{~mL}$ of methanol and then by aqueous formic acid solution (1 mL/L). $1 \mathrm{~mL}$ of the beer sample was passed through the SPE column, washed by $3 \mathrm{~mL}$ of aqueous formic acid solution $(1 \mathrm{~mL} / \mathrm{L})$, then by $3 \mathrm{~mL}$ of methanol, and gently dried by vacuum. Analyte was eluted from the sorbent by $2 \mathrm{~mL}$ of $5 \%$ ammonium hydroxide in methanol. Eluent was dried under a gentle argon flow at $50{ }^{\circ} \mathrm{C}$ in heat-block Pierce Reacti-Therm (Thermo Scientific, USA). Derivatization of dry residuum was performed by $200 \mu \mathrm{L}$ of pyridine and $100 \mu \mathrm{L}$ of BSTFA at $70{ }^{\circ} \mathrm{C}$ for $30 \mathrm{~min}$.

\subsection{Fortified samples and blanks}

Aqueous solution of formic acid (1 mL/L) was used as a blank sample. Beer samples, previously degassed and acidified (1 mg/L), were fortified by stock solution of melamine $(516 \mathrm{mg} / \mathrm{L}$ in methanol) to concentrations 0.5 or $2.5 \mathrm{mg} / \mathrm{L}$ for the purpose of method optimization, validation, and latter quantification by a method of two-level standard addition. The preparation procedure for blank and fortified samples was the same as for the test samples.

\subsection{Analysis by GC-MS/MS}

Analyses were performed by gas chromatograph Agilent 7890B (Agilent Technologies, USA) with column HP-5MS-UI (5\% phenyldimethylpolysiloxan, $30 \mathrm{~m} \times$ $0.25 \mathrm{~mm} \times 0.25 \mu \mathrm{m})$. The sample injection of $2 \mu \mathrm{l}$ was made in a split mode $(3: 1)$ at $250{ }^{\circ} \mathrm{C}$, with a constant flow of helium of $1 \mathrm{~mL} / \mathrm{min}$ ( 6.0 purity, Air Products, Czech Republic). Septum purge was set to $3 \mathrm{~mL} / \mathrm{min}$ and a gradient temperature program was $75^{\circ} \mathrm{C}(1 \mathrm{~min})$ $-10{ }^{\circ} \mathrm{C} / \mathrm{min}-220^{\circ} \mathrm{C}(2 \mathrm{~min})-10^{\circ} \mathrm{C} / \mathrm{min}-260^{\circ} \mathrm{C}(0 \mathrm{~min})$ $-25^{\circ} \mathrm{C} / \mathrm{min}-300^{\circ} \mathrm{C}(2 \mathrm{~min})$. Trimethylsilyl derivative of melamine was detected by the triple quadrupole mass spectrometer Agilent 7000D (Agilent Technologies, USA), with interface temperature set to $250^{\circ} \mathrm{C}$. Electron ionization was carried out at $70 \mathrm{eV}$ at $230^{\circ} \mathrm{C}$, and collision energy of nitrogen gas was set at $10 \mathrm{eV}$ ( 6.0 purity, Air Products, Czech Republic). Detection in the product ion mode of the parent ion $m / z 327$ was adapted. Optimization, validation parameters and quantification results were calculated from the peak area of the quantification ion $\mathrm{m} / \mathrm{z} 171$. 


\subsection{Method Development}

$\mathrm{N}, \mathrm{N}, \mathrm{N}$-tris(trimethylsilyl)derivative of melamine (1.7 $\mathrm{mmg} / \mathrm{L}$ ) prepared by derivatization of dry residuum of melamine stock solution by BSTFA at $70{ }^{\circ} \mathrm{C}$ for $30 \mathrm{~min}$, was used for the optimization of chromatographic and detection conditions. Detection in the full scan mode was firstly used for the analyte identification, then only detection in the product ion mode of the parent ion $m / z 327$ was adapted. In order to find the appropriate volume for quantitative extraction of melamine from SPE sorbent, the fortified samples ( $2.5 \mathrm{mg} / \mathrm{L}$ of melamine) were individually eluted by $1,2,3,5,6,7,8$, and $9 \mathrm{~mL}$ of $5 \%$ ammonium hydroxide in methanol. Absolute recovery and matrix effect were calculated according to Caban (2012). All samples were prepared in triplicate. Finally, the limit of detection (LOD), the limit of quantification (LOQ), and extended uncertainty were calculated from a standard deviation of ten analyses of fortified beer samples with melamine concentration at $0.5 \mathrm{mg} / \mathrm{L}$. Quantification in real beer samples was performed by the methodology of two-level standard addition, with melamine fortified beer sample at 0.5 and $2.5 \mathrm{mg} / \mathrm{L}$.

\section{Results and Discussion}

\subsection{Method Development}

Acquired GC-MS full-scan spectrum of trimethylsilyl derivative of melamine standard was used for the confirmation of target analyte eluting at $19.1 \mathrm{~min}$, in accordance with reference NIST library (CAS\#: 60585-93-5; NIST\#: 384197). Detection of the analyte was further conducted in the product-ion mode to prevent false positive results. The highest response for parent ion $(\mathrm{m} / \mathrm{z} 327)$ fragmentation was observed at collision energy $10 \mathrm{eV}$.

Previously reported work documented SPE procedure for the purpose of quantitative determination of melamine (Cai, 2008). However, the procedure was developed for milk, thus it can be assumed that different interferents were retained by SPE sorbent than those from beer, which could further affect the recovery as well as the analyte elution. First, elution volumes of $5 \%$ solution of ammonia were compared in order to elute the highest possible amount of analyte from SPE sorbent. Figure 2 shows a comparison of relative responses which depend on individual elution volumes. Relative responses were calculated from areas of the quantitative fragment $m / z 171$, and, in this case, they reflect an approximate quantity of the analyte. The highest relative response was achieved by using $2 \mathrm{~mL}$ of $5 \%$ ammonia solution. As can be seen, higher volumes of elution solvent result in lower responses. It is assumed, the higher volume of elu- tion agent is used, the more interferences that possibly suppress the analyte response are eluted. Furthermore, it was experimentally observed that longer air exposition of the elution agent was inversely proportional to its efficiency due to its high volatility. Hence, it is essential to work with freshly prepared ammonia solution and expose it minimally to the laboratory environment. Non-systematic differences among relative recoveries (Figure 2) were most likely the results of combination of these both phenomena. In addition, the volume of $1 \mathrm{~mL}$ of ammonia solution led to a minimum response, as the volume seems to be too low to elute enough amount of analyte from the SPE cartridge. An additional parameter of absolute recovery was also calculated (see 2.5 Method Development). First approach was absolute recovery determination by using a sample of melamine external standard. Even though the mean absolute recovery was 83.00\% (RSD 0.01\%) which was consistent with the model method (Cai, 2008), the estimated matrix effect $(<10.00 \%)$ had a high variability (RSD $>60.00 \%)$. For this reason, the method of a standard addition for determination of absolute recovery and further quantification was adapted. This second approach appears to be effective in compensating the matrix effect that could occur during analysis of variable samples, such as special beers. At final, the calculated mean value of absolute recovery was $102,00 \%(\operatorname{RSD}=15,55 \%)$.

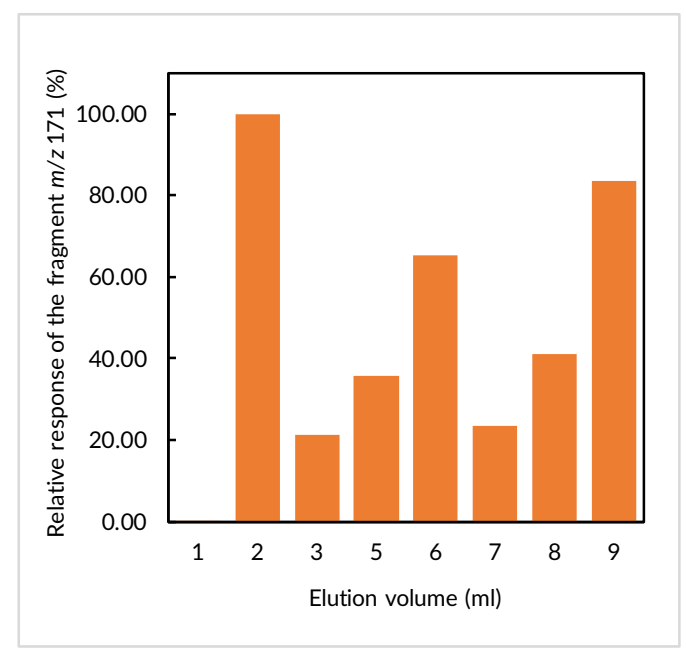

Figure 2 Comparison of relative peak area of fragment m/z 171 on elution volume used to elute melamine from SPE sorbent

Furthermore, extended uncertainty, LOQ and LOD (Table 1 - left) of the method were calculated (see 2.5 Method Development). According to the legislative the maximum permitted value of melamine is stated in $\mathrm{mg} / \mathrm{kg}$ 
units, thus, concentrations LOQ, LOD and limit concentration $2.5 \mathrm{mg} / \mathrm{L}$ were recalculated into required units $\mathrm{mg} /$ $\mathrm{kg}$ (Table 1 - right). As it can be seen from the results, all three concentration levels (LOQ LOD and limit concentration) in the units $\mathrm{mg} / \mathrm{L}$ and $\mathrm{mg} / \mathrm{kg}$ were equivalent with insignificant estimation errors. Hence it can be concluded that the method is sufficient to accomplish the legislative requirements. of beer by melamine is very low. On the other hand, it was observed that plastic kitchenware containing melamine can contaminate food after microwave heating (de Lourdes Mendes, 2014), which could lead to a question if contamination from brewing ware or packing material is possible.

Table 1 Validation parameters of the method (left) and appropriate concentrations in unit $\mathrm{mg} / \mathrm{kg}$ (right)

\begin{tabular}{|c|c|c|c|c|}
\hline Parameter & Value (mg/L) & Concentration & Value* (mg/kg) & $\begin{array}{l}\text { Estimation error* } \\
\qquad\left(10^{-3} \mathrm{mg} / \mathrm{kg}\right)\end{array}$ \\
\hline LOD & 0.1 & LOD & 0.1 & \pm 0.1 \\
\hline LOQ & 0.4 & LOQ & 0.4 & \pm 0.4 \\
\hline $\begin{array}{l}\text { Extended } \\
\text { uncertainty }\end{array}$ & \pm 0.1 & Limit concentration ( $2.5 \mathrm{mg} / \mathrm{L})$ & 2.5 & \pm 2.2 \\
\hline
\end{tabular}

\subsection{Method Application}

In order to demonstrate the practical application of the method on real beer samples, 20 samples of commercial lagers and other beer styles were analyzed. The quantification was performed by the method of two-level standard addition using spiked samples of beer to 0.5 and $2.5 \mathrm{mg} / \mathrm{L}$ concentration of melamine. The example of sample responses of original and spiked beer is shown in Figure 3, and it could represent all test samples as they were all evaluated to have concentrations of melamine under the limit of quantification $(<0.4 \mathrm{mg} / \mathrm{L})$.

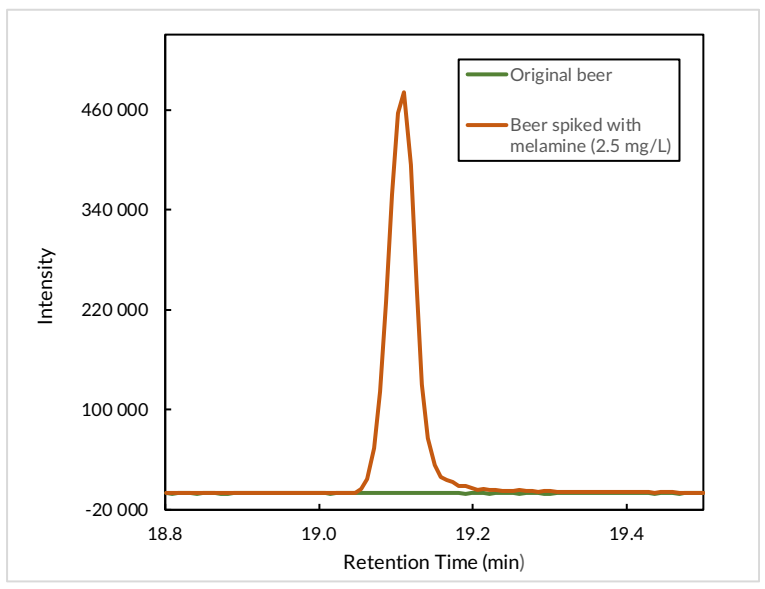

Figure 3 Comparison of peaks of quantification fragment $\mathrm{m} / \mathrm{z}$ 171 of original and spiked beer sample to $2.5 \mathrm{mg} / \mathrm{L}$

This is the first study that focuses on levels of melamine in beer. Also, the quality of beer is not generally evaluated according to protein content, thus it can be assumed that the probability of purposed contamination

\section{Conclusion}

The method for determination of melamine in beer and beer-type samples using GC-MS/MS was developed. The average absolute recovery of the preparation procedure was $102.00 \%$ (RSD $=15.55 \%$ ). Limits of detection and quantification were $0.1 \mathrm{mg} / \mathrm{L}$, and $0.4 \mathrm{mg} / \mathrm{L}$, respectively. The extended uncertainty of the melamine determination is $0.1 \mathrm{mg} / \mathrm{L}$. The quantification method of two-level standard addition was chosen to compensate possible deviations in matrix effect. All twenty test samples had concentration of melamine under the limit of quantification $(<0.4 \mathrm{mg} / \mathrm{L})$.

\section{Acknowledgement}

The study was supported by the Ministry of Agriculture of the Czech Republic within the institutional support No. MZE-R01918, and by project of Specific University Research SVV260560.

\section{References}

Beltrán-Martinavarro, B., Peris-Vicente, J., Carda-Broch, S., Esteve-Romero, J. (2014). Development and validation of a micellar liquid chromatography-based method to quantify melamine in swine kidney. Food Control, 46, 168-173. https://doi.org/10.1016/j.foodcont.2014.05.027

Beltrán-Martinavarro, B., Peris-Vicente, J., Rambla-Alegre, M. (2013). Quantification of Melamine in Drinking Water and Wastewater by Micellar Liquid Chromatography. J. AOAC Int., 96, 870-874. https:// doi.org/10.5740/jaoacint.12-248

Caban, M., Migowska, N., Stepnowski, P. (2012). Matrix effects and recovery calculations in analyses of pharmaceuticals based on the deter- 
mination of $\beta$-blockers and $\beta$-agonists in environmental samples. J. Chromatogr. A, 1258, 117-127. https://doi.org/10.1016/j.chroma.2012.08.029

Cai, M., Zou, Y. (2008). Trace-Level Analysis of Melamine in Milk Products on Agilent 7890A/5975C GC/MSD Using a New Agilent J\&W DB-5ms Ultra Inert Column and SampliQ SCX Cartriges. Agilent Technologies, Inc. [online] https://www.agilent.com/cs/library/applications/5990-3282EN.pdf [cit. 2020-03-18] [cit. 2020-03-18].

Commission Regulation (EU) No. 594/2012. Official Journal of the European Union. 176, 43-45.

de Lourdes Mendes Finete, V., Gouvea, M.M., de Carvalho Marques, F.F., Netto, A.D.P. (2014). Characterization of newfound natural luminescent properties of melamine, and development and validation of a method of high performance liquid chromatography with fluorescence detection for its determination in kitchen plastic ware. Talanta, 123, 128-134. https://doi.org/10.1016/j.talanta.2014.02.012

Dobson, R., Motlagh, M., Quijano, M., Cambron, R.T., Baker, T.R., Pullen, A.M., Regg, B.T., Bigalow-Kern, A.S., Vennard, T., Fix, A., Reimschuessel, R., Overmann, G., Shan, Y., Daston, G.P. (2008). Identification and Characterization of Toxicity of Contaminants in Pet Food Leading to an Outbreak of Renal Toxicity in Cats and Dogs. Toxicol. Sci., 106, 251-262. https://doi.org/10.1093/toxsci/kfn160

Demirhan, B.E.R., Demirhan, B., Bas, S.Y., Yentur, G., Oktem, A.B. (2015). Investigation of Melamine Presence in Canned Tuna Fish by Capillary Zone Electrophoresis Method. Tarim. Bilim. Derg., 21, 310-315.

Faraji, M., Adeli, M. (2017). Sensitive determination of melamine in milk and powdered infant formula samples by high-performance liquid chromatography using dabsyl chloride derivatization followed by dispersive liquid-liquid microextraction. Food Chem., 221, 139-146. https://doi.org/10.1016/j.foodchem.2016.10.002

Marco-Peiró, S., Beltrán-Martinavarro, B., Rambla-Alegre, M. (2012). Validation of an analytical methodology to quantify melamine in body fluids using micellar liquid chromatography. Talanta, 88, 617-622. https://doi.org/10.1016/j.talanta.2011.11.047
Mirzajani, R., Tavaf, N. (2016). Rapid and Highly Sensitive Determination of Melamine in Different Food Samples by Corona Discharge Ion Mobility Spectrometry after Dispersive Liquid-Liquid Microextraction. J. Braz. Chem. Soc., 27, 1657-1666. https://doi.org/10.5935/01035053.20160045

Nascimento, C., Rocha, D., Rocha, F. (2015). A fast and environmental friendly analytical procedure for determination of melamine in milk exploiting fluorescence quenching. Food Chem., 169, 314-319. https://doi.org/10.1016/j.foodchem.2014.07.144

Nochetto, C., Stine, C., Reimschuessel, R. (2013). Development and Validation of a Method for the Simultaneous Determination and Confirmation of Melamine and Cyanuric Acid in Fish Kidney by LC/MS/MS J. AOAC Int., 96, 663-669. https://doi.org/10.5740/jaoacint.12-303

Peris-Vicente, J., Albiol-Chiva, J., Roca-Genovés, P. (2016). Advances on melamine determination by micellar liquid chromatography: A review, J. Liq. Chromatogr. Relat. Technol., 39, 325-338. https://doi.or g/10.1080/10826076.2016.1152482

Skinner, C., Thomas, J., Osterloh, J. (2010). Melamine Toxicity. J. Med. Toxicol., 6, 50-55. https://doi.org/10.1007/s13181-010-0038-1

WHO - World Health Organisation (2008). Toxicological and health aspects of melamine and cyanuric acid. [online] https://www.who.int/ foodsafety/publications/chem/Melamine_report09.pdf [cit. 202003-18] [cit. 2020-03-18].

Wu, B., Wang, Z., Zhao, D. (2012). A novel molecularly imprinted impedimetric sensor for melamine determination. Talanta, 101, 374-381. https://doi.org/10.1016/j.talanta.2012.09.044

Zhao, R., Sun, S., Hao, W. (2019). A Highly Sensitive Determination for the Melamine in Milk on MIL-101/AuNPs/CTS-PVP-rGO/GCE Electrochemical Sensor". Russ. J. Electrochem. 55, 651-662.

Zhao, S.-L. (2013). GC/MS/MS Analysis of Melamine in Milk Powder with Agilent Bond Elut Plexa PCX. Agilent Technologies, Inc. [online] http://hpst.cz/sites/default/files/attachments/5991-2495engcmsms-analysis-melamine-milk-powder-bond-elut-plexa-pcx.pdf [cit. 2020-03-18]. 